\title{
Class II:2 malocclusion-prevalence and progression of labial gingival recessions during Herbst-Multibracket appliance treatment
}

\author{
N. C. Bock ${ }^{1} \cdot$ S. Killat $^{2} \cdot$ S. Ruf ${ }^{1}$
}

Received: 28 August 2019 / Accepted: 12 February 2020 / Published online: 27 February 2020

(C) The Author(s) 2020

\begin{abstract}
Objectives To determine the prevalence, incidence, and changes in magnitude of labial gingival recessions (LGR) in class II:2 patients during Herbst-Multibracket appliance (Herbst-MBA) treatment (Tx) plus retention.

Subjects and methods All class II:2 patients of the Department of Orthodontics, University of Giessen, Germany who completed Herbst-MBA Tx (mean pre-Tx age 15.6 years). The cohort had undergone a Herbst phase (mean 8.1 months) as well as a subsequent MBA phase (mean 14.4 months). Study casts were evaluated from pre-Tx and after Herbst-MBA Tx plus $\geq 24$ months of retention. Results Ratable pre-Tx and post-retention study casts (total observation period 53.5 \pm 10.3 months) were available from 94 out of 173 patients. No significant difference existed regarding pre-Tx LGR data between patients with and without complete records. The prevalence for teeth with LGR $\geq 0.5 \mathrm{~mm}$ was $1.4 \%$ pre-Tx respectively $6.7 \%$ post-retention. The highest values of up to $5.3 \%$ (pre-Tx) and $20.2 \%$ (post-retention) were determined for the upper first premolars and lower central incisors. Incidence values of $4.7 \%$ (all teeth) and up to $14.9 \%$ (upper first right premolars) respectively $11.1 \%$ (lower central incisors) were calculated (LGR $\geq 0.5 \mathrm{~mm}$ ). The overall LGR mean magnitudes were $0.01 \mathrm{~mm}$ pre-Tx respectively $0.06 \mathrm{~mm}$ post-retention.

Conclusions For the prevalence of LGR $\geq 0.5 \mathrm{~mm}$ an average increase of $5.3 \%$ was determined during $\approx 4.5$ years of HerbstMBA Tx plus retention. The highest incidence was seen for lower central incisors and upper right premolars (11.1/14.9\%). The overall LGR mean magnitude increased by $0.05 \mathrm{~mm}$.

Clinical relevance Herbst-MBA Tx is a common approach for class II:2 malocclusions. Very little, however, is known regarding LGR development in respective patients.
\end{abstract}

Keywords Class II:2 $\cdot$ Herbst treatment $\cdot$ Labial gingival recessions $\cdot$ Prevalence $\cdot$ Incidence $\cdot$ Magnitude

\section{Introduction}

The literature is controversial regarding if and to what extent the emergence of labial gingival recessions (LGR) can be considered a result of orthodontic treatment (Tx). Since the 1970s, it has been discussed whether the development of LGR should be regarded as the result of a labial movement of teeth,

Electronic supplementary material The online version of this article (https://doi.org/10.1007/s00784-020-03243-2) contains supplementary material, which is available to authorized users.

N. C. Bock

niko.c.bock@dentist.med.uni-giessen.de

1 Department of Orthodontics, University of Giessen, Schlangenzahl 14, 35392 Giessen, Germany

2 Stuttgart, Germany which might predispose them to bone dehiscences and periodontal attachment loss $[1,2]$. Until today, however, no respective consensus has been reached.

The available systematic reviews report both little to no clinically relevant effect $[3,4]$ or small negative effects [5] of orthodontic Tx on periodontal health. Similarly, various investigations have determined a higher prevalence for LGR after orthodontic Tx compared to untreated controls $[6,7]$. Particularly the proclination of lower incisors has been regarded as a risk factor [8-10]. Recent studies, on the other hand, could not confirm this presumption [11, 12].

Herbst appliance Tx is known to often result in lower incisor proclination [13-15]. Alveolar bone loss on the buccal surface of the lower incisors during class II Herbst Tx in CBCT amounts to an average of $\leq 0.2 \mathrm{~mm}[16]$ and is unpredictable on the individual level — even when adding skeletal anchorage [17]. Nevertheless, neither a clinically significant adverse short- or long-term impact of Herbst appliance Tx on 
periodontal health $[13,18-20]$ nor an association between the amount of proclination and the prevalence/incidence of LGR [15] have been determined so far.

Unfortunately, the majority of available studies only looked at the condition of the lower incisors and evaluated rather selected patient cohorts fulfilling specific, fairly strict inclusion criteria. While some more representative data exist for class II:1 Tx [18], no investigation has specifically looked at class II:2 malocclusions so far.

\section{Aim}

It was the objective of the present investigation to assess the prevalence, incidence, and magnitude of LGR on all permanent teeth after Herbst-Multibracket appliance (MBA) Tx in a large class II:2 cohort of consecutive patients, unselected in terms of Tx outcome.

\section{Material and methods}

The archive of the Department of Orthodontics, University of Giessen, Germany was screened for all patients who had undergone Herbst-MBA Tx since establishing this Tx approach in 1986. The records were evaluated regarding the following inclusion criteria and in case of fulfilment the respective patients were consecutively included:

- Class II:2

- Herbst-MBA Tx completed

- Study casts from before Tx (T0) and/or $\geq 24$ months after Herbst-MBA Tx and retention (T1) available

The Tx protocol included a Herbst phase using a cast-splint Herbst appliance (Dentaurum GmbH, Germany) and a subsequent MBA phase where two different types of labial straightwire MBAs including class II elastics were applied. In approximately one-third of the patients, an initial short phase of fixed appliance $\mathrm{Tx}$ for upper incisor proclination was undertaken to enable Herbst appliance insertion and adjustment in an incisal edge-to-edge relationship. In addition, approximately onetenth of the patients had received maxillary transverse expansion using fixed or removable appliances before starting Herbst Tx; in the remaining patients, Tx was started directly with the insertion of the Herbst appliance.

All study casts were visually inspected in terms of accuracy and excluded in case of "altered" looking gingival conditions preventing from reliable measurements like for example the appearance of marked swelling, air blows or other artefacts. The study casts from T0 and T1 were evaluated for LGR on all fully erupted teeth except the wisdom teeth. The distance between the cemento-enamel junction and the deepest point of the gingival margin was assessed and - in case of a positive value-defined as LGR. These measurements were performed using a manual calliper (HSL247-52, Karl Hammacher GmbH, Solingen, Germany) and were rounded to the nearest $0.5 \mathrm{~mm}$. The mean value and standard deviation as well as the minimum, maximum and median values were assessed separately for each tooth to allow for a most comprehensive comparison with the literature.

One single operator (-) performed all measurements. To determine observer reliability, the study casts of 20 consecutive patients were assessed twice with a time interval of at least 2 weeks between the two measurements. The mean method error was calculated as $0.07 \pm 0.08$ using the Dahlberg Formula and Kendall's Tau correlation coefficient as 0.844 revealing a high consistency [21].

LGR prevalence $(\%)$ and LGR magnitude $(\mathrm{mm})$ were assessed for the complete patient sample at $\mathrm{T} 0$ and $\mathrm{T} 1$; LGR incidence (\%) during T0-T1 was determined and statistically analysed exclusively for patients with "complete" records, i.e. study casts available from $\mathrm{T} 0$ and $\mathrm{T} 1$.

IBM ${ }^{\circledR}$ SPSS ${ }^{\circledR}$ Statistics Version 23 (IBM Corporation, Armonk, NY, USA) software as well as Microsoft Excel 2010 were used for the statistical analyses. No sample size calculation was performed because of the explorative character of the study. But to determine a possible trend, the pre-Tx and post-retention data of patients with "complete" records were compared separately for each tooth (T0 vs. T1) regarding LGR prevalence (McNemar test) and LGR magnitude (Wilcoxon signed-rank test). The significance level was $p<0.05$.

\section{Results}

The total cohort of class II:2 patients who had completed Herbst-MBA Tx since 1986 comprised of 177 patients (Fig. 1). As no significant difference existed between those patients with "complete" records (ratable study casts from T0 and $\mathrm{T} 1 ; n=94)$ respectively "incomplete" records (ratable study casts from T0/T1 only; $n=79 / n=0$ ), the cohort with "complete" records was considered representative for the entire sample (Supplementary Tables 1 and 2). So, exclusively, the data of this group are presented in detail. The mean active Tx duration was $22.6 \pm 7.2$ months and the mean post-Tx observation period $29.1 \pm 7.5$ months. From T0 to T1, the overbite had changed from $5.3 \pm 1.6$ to $1.6 \pm 0.8 \mathrm{~mm}$ and the molar relationship from $0.9 \pm 0.3$ cusp widths class II to $0.0 \pm$ 0.2 (class I). For retention, upper and/or lower bonded canineto-canine retainers, removable upper and/or lower retention plates or a combination of both were used, plus in about one-third of the patients an activator. At follow-up, a lower bonded retainer was still worn by $90 \%$ of the patients while an upper bonded/removable retainer was worn by $64 \% / 19 \%$. 
Fig. 1 Patient flow chart. The numbers of class II: 2 patients who started/completed Herbst-MBA Tx and a follow-up observation period of $\geq 24$ months are given, as well as the numbers of ratable/ included pre- and post-retention study casts

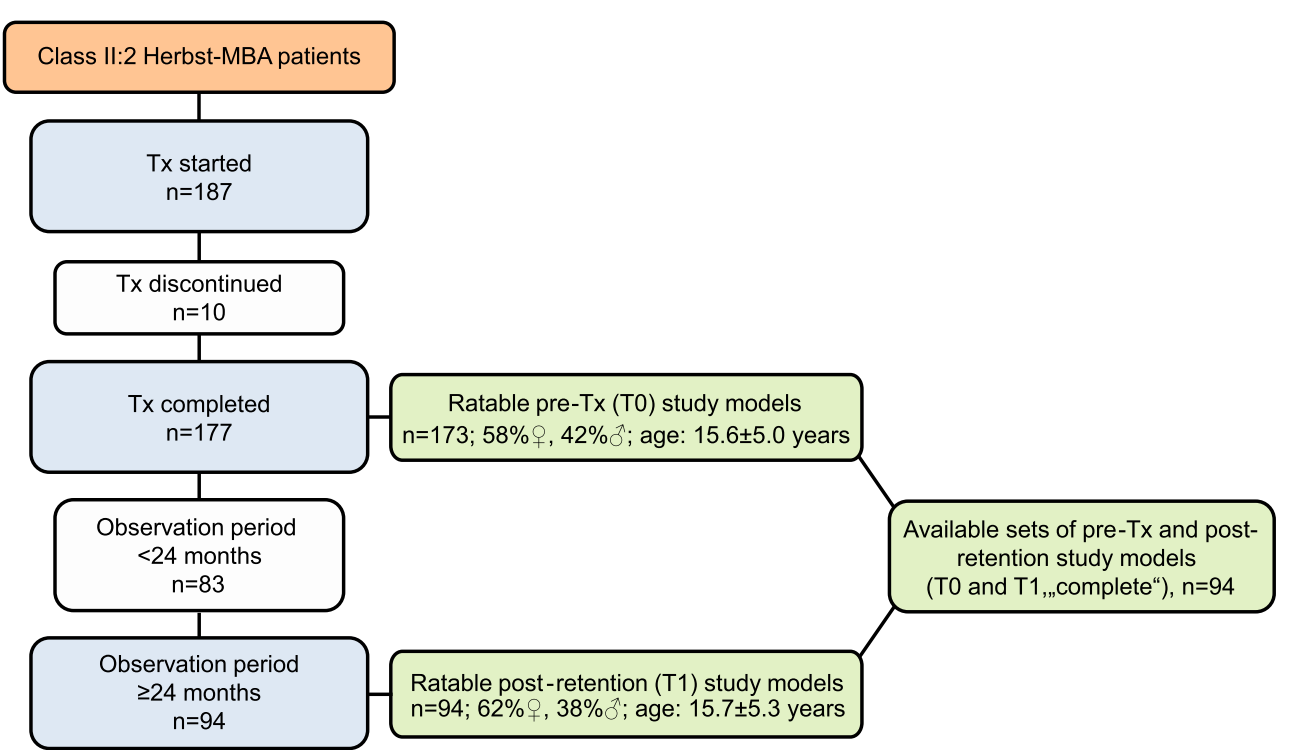

\section{Prevalence and magnitude of LGR $(n=94)$}

Evaluating the overall pre-Tx condition (T0), the prevalence for LGR with a magnitude $\geq 0.5 \mathrm{~mm}$ was $1.4 \%$ for all included 2601 teeth (Table 1); the median magnitude was $0.0 \mathrm{~mm}$, and the maximum was $1.5 \mathrm{~mm}$ (Table 2). The upper first premolars showed the highest prevalence value of $5.3 \%$;

Table 1 Prevalence (\%) of labial gingival recession for the teeth 17-47 before Tx (T0) and after Herbst-MBA Tx plus a retention period of $\geq$ 24 months (T1) in 94 individuals. Labial gingival recession categorized nevertheless, no tooth presented LGR with a magnitude $\geq$ $2.0 \mathrm{~mm}$ (Fig. 2a, b; Table 1).

After Tx plus a post-Tx retention period of on average 29 months (T1), $6.7 \%$ of all assessed 2601 teeth exhibited LGR with a magnitude $\geq 0.5 \mathrm{~mm}$ (Table 1 ). The median magnitude was $0.0 \mathrm{~mm}$, and the maximum was $3.0 \mathrm{~mm}$ (Table 2). The most frequently affected teeth were the upper first and the

\begin{tabular}{|c|c|c|c|c|c|c|c|c|c|c|c|c|c|c|c|c|c|c|c|c|c|c|c|c|c|c|c|c|c|}
\hline \begin{tabular}{l|l}
$\mathrm{L}$ \\
$\mathrm{G}$ \\
$\mathrm{R}$
\end{tabular} & $\begin{array}{c}\text { None } \\
(<0.5 \mathrm{~mm})\end{array}$ & \multicolumn{2}{|c|}{\begin{tabular}{c|c}
100 & 99.0 \\
$p=1.000$
\end{tabular}} & \multicolumn{2}{|c|}{\begin{tabular}{c|c|}
98.9 & 97.0 \\
$p=0.625$
\end{tabular}} & \multicolumn{2}{|c|}{$\begin{array}{c}97.8 \mid 87.9 \\
p=0.006\end{array}$} & \multicolumn{2}{|c|}{\begin{tabular}{|c|c|}
94.7 & 79.8 \\
$p=0.001$
\end{tabular}} & \multicolumn{2}{|c|}{\begin{tabular}{l|l|}
100 & 94.0 \\
$p=0.063$
\end{tabular}} & \multicolumn{2}{|c|}{\begin{tabular}{l|l|}
100 & 95.0 \\
$p=0.063$
\end{tabular}} & \multicolumn{2}{|c|}{\begin{tabular}{l|l|}
100 & 97.0 \\
$p=0.250$
\end{tabular}} & \multicolumn{2}{|c|}{\begin{tabular}{l|l|}
100 & 98.0 \\
$p=0.500$
\end{tabular}} & \multicolumn{2}{|c|}{\begin{tabular}{l|l|}
100 & 95.0 \\
$p=0.063$
\end{tabular}} & \multicolumn{2}{|c|}{\begin{tabular}{|l|l|}
100 & 96.0 \\
$p=0.125$
\end{tabular}} & \multicolumn{2}{|c|}{\begin{tabular}{|c|c|}
94.7 & 86.9 \\
$p=0.039$
\end{tabular}} & \multicolumn{2}{|c|}{$\begin{array}{c}98.9 \mid 92.9 \\
p=0.07\end{array}$} & \multicolumn{2}{|c|}{\begin{tabular}{|l|l|}
97.9 & 97.0 \\
$p=1.000$
\end{tabular}} & \multicolumn{2}{|c|}{\begin{tabular}{l|l|}
100 & 99.0 \\
$p=1.000$
\end{tabular}} \\
\hline p & $\begin{array}{c}\geq 0.5-<1.0 \\
\mathrm{~mm}\end{array}$ & 0.0 & 0.0 & 0.0 & 1.0 & 1.1 & 8.1 & 2.1 & 10.1 & 0.0 & 2.0 & 0.0 & 3.0 & 0.0 & 1.0 & 0.0 & 1.0 & 0.0 & 3.0 & 0.0 & 1.0 & 2.1 & 8.1 & 0.0 & 5.1 & 0.0 & 2.0 & 0.0 & 0.0 \\
\hline e & $\begin{array}{c}\geq 1.0-<2.0 \\
\mathrm{~mm}\end{array}$ & $\% \quad 0.0$ & 1.0 & 1.1 & 2.0 & 1.1 & 4.0 & 3.2 & 8.1 & 0.0 & 3.0 & 0.0 & 2.0 & 0.0 & 2.0 & 0.0 & 1.0 & 0.0 & 2.0 & 0.0 & 2.0 & 3.2 & 3.0 & 1.1 & 2.0 & 2.1 & 1.0 & 0.0 & 1.0 \\
\hline e & $\begin{array}{l}\geq 2.0 \\
\mathrm{~mm}\end{array}$ & 0.0 & 0.0 & 0.0 & 0.0 & 0.0 & 0.0 & 0.0 & 2.0 & 0.0 & 1.0 & 0.0 & 0.0 & 0.0 & 0.0 & 0.0 & 0.0 & 0.0 & 0.0 & 0.0 & 1.0 & 0.0 & 2.0 & 0.0 & 0.0 & 0.0 & 0.0 & 0.0 & 0.0 \\
\hline C & Total & 0.0 & 1.0 & 1.1 & 3.0 & 2.2 & 12.1 & 5.3 & 20.2 & 0.0 & 6.0 & 0.0 & 5.0 & 0.0 & 3.0 & 0.0 & 2.0 & 0.0 & 5.0 & 0.0 & 4.0 & 5.3 & 13.1 & 1.1 & 7.1 & 2.1 & 3.0 & 0.0 & 1.0 \\
\hline \multirow{4}{*}{\multicolumn{2}{|c|}{ Occasion }} & T0 & T1 & TO & $\mathrm{T} 1$ & T0 & T1 & TO & T1 & T0 & T1 & T0 & $\mathrm{T} 1$ & T0 & T1 & T0 & T1 & T0 & T1 & T0 & $\mathrm{T} 1$ & TO & T1 & T0 & $\mathrm{T} 1$ & TO & $\mathrm{T} 1$ & T0 & $\mathrm{T} 1$ \\
\hline & & \multicolumn{2}{|c|}{17} & \multicolumn{2}{|c|}{16} & \multicolumn{2}{|c|}{15} & \multicolumn{2}{|c|}{14} & \multicolumn{2}{|c|}{13} & \multicolumn{2}{|c|}{12} & \multicolumn{2}{|c|}{11} & \multicolumn{2}{|c|}{21} & \multicolumn{2}{|c|}{22} & 2 & & 2 & 44 & 2 & 5 & 2 & 26 & 2 & 7 \\
\hline & & & & & & & & & & & & & & & Too & & & & & & & & & & & & & & \\
\hline & & & 7 & & 46 & 4 & 5 & 4 & 4 & 4 & & 4 & & 4 & & 3 & & 3 & & 3 & & 3 & 4 & 3 & 5 & 3 & 36 & 3 & 7 \\
\hline & Occasion & TO & $\mathrm{T} 1$ & TO & $\mathrm{T} 1$ & T0 & T1 & TO & T1 & T0 & T1 & TO & $\mathrm{T} 1$ & T0 & $\mathrm{T} 1$ & TO & T1 & TO & T1 & T0 & $\mathrm{T} 1$ & \begin{tabular}{|l|} 
TO \\
\end{tabular} & T1 & T0 & $\mathrm{T} 1$ & TO & $\mathrm{T} 1$ & T0 & $\mathrm{T} 1$ \\
\hline $\mathbf{G}$ & Total & 0.0 & 0.0 & 2.2 & 2.0 & 2.2 & 9.1 & 4.3 & 9.1 & 1.1 & 7.0 & 0.0 & 5.0 & 1.1 & 12.2 & 2.1 & 13.1 & 0.0 & 4.0 & 2.2 & 8.1 & 3.2 & 7.1 & 1.1 & 7.0 & 2.2 & 1.0 & 0.0 & 1.0 \\
\hline$p$ & $\begin{array}{l}\geq 2.0 \\
\mathrm{~mm}\end{array}$ & 0.0 & 0.0 & 0.0 & 0.0 & 0.0 & 0.0 & 0.0 & 1.0 & 0.0 & 1.0 & 0.0 & 0.0 & 0.0 & 0.0 & 0.0 & 0.0 & 0.0 & 0.0 & 0.0 & 1.0 & 0.0 & 0.0 & 0.0 & 1.0 & 0.0 & 0.0 & 0.0 & 1.0 \\
\hline e & $\begin{array}{c}\geq 1.0-<2.0 \\
\mathrm{~mm}\end{array}$ & $\% \quad 0.0$ & 0.0 & 2.2 & 1.0 & 2.2 & 6.1 & 4.3 & 8.1 & 1.1 & 4.0 & 0.0 & 3.0 & 1.1 & 7.1 & 2.1 & 9.1 & 0.0 & 3.0 & 2.2 & 5.1 & 3.2 & 7.1 & 1.1 & 5.0 & 2.2 & 0.0 & 0.0 & 0.0 \\
\hline a & $\begin{array}{c}\geq 0.5-<1.0 \\
\mathrm{~mm}\end{array}$ & 0.0 & 0.0 & 0.0 & 1.0 & 0.0 & 3.0 & 0.0 & 0.0 & 0.0 & 2.0 & 0.0 & 2.0 & 0.0 & 5.1 & 0.0 & 4.0 & 0.0 & 1.0 & 0.0 & 2.0 & 0.0 & 0.0 & 0.0 & 1.0 & 0.0 & 1.0 & 0.0 & 0.0 \\
\hline $\mid \begin{array}{l}n \\
c\end{array}$ & $\begin{array}{c}\text { None } \\
(<0.5 \mathrm{~mm})\end{array}$ & $\begin{array}{l}100 \\
p=1\end{array}$ & $\begin{array}{c}100 \\
000\end{array}$ & $\begin{array}{r}97.8 \\
p=1 .\end{array}$ & $\begin{array}{l}98.0 \\
.000\end{array}$ & $\begin{array}{r}97.8 \\
p=0 .\end{array}$ & $\begin{array}{l}90.9 \\
.016\end{array}$ & $\begin{array}{c}95.7 \\
p=0 .\end{array}$ & $\begin{array}{l}90.9 \\
.125\end{array}$ & $\begin{array}{r}98.9 \\
p=0 .\end{array}$ & $\begin{array}{l}93.0 \\
031\end{array}$ & $\begin{array}{l}100 \\
p=0 .\end{array}$ & $\begin{array}{l}95.0 \\
063\end{array}$ & $\begin{array}{r}98.9 \\
p=0 .\end{array}$ & $\begin{array}{l}87.8 \\
001\end{array}$ & $\begin{array}{r}97.9 \\
p=0 .\end{array}$ & $\begin{array}{l}86.9 \\
.001\end{array}$ & $\begin{array}{l}100 \\
p=0 .\end{array}$ & $\begin{array}{l}96.0 \\
125\end{array}$ & $\begin{array}{r}97.8 \\
p=0 .\end{array}$ & $\begin{array}{l}91.9 \\
031\end{array}$ & $\begin{array}{r}96.8 \\
p=0\end{array}$ & $\begin{array}{l}92.9 \\
.125\end{array}$ & $\begin{array}{c}98.9 \\
p=0 .\end{array}$ & $\begin{array}{l}93.0 \\
031\end{array}$ & $\begin{array}{l}97.8 \\
p=1\end{array}$ & $\begin{array}{l}99.0 \\
.000\end{array}$ & $\begin{array}{l}100 \\
p=1\end{array}$ & $\begin{array}{l}99.0 \\
.000\end{array}$ \\
\hline
\end{tabular}


Table 2 Magnitude ( $\mathrm{mm}$ ) of labial gingival recession for the teeth 1747 before Tx (T0) and after Herbst-MBA Tx plus a retention period of $\geq$ 24 months (T1) in 94 individuals. The mean value and standard deviation as well as the median, minimum and maximum values are given. In addition, the $p$ value of the statistical comparison (T0 vs. T1) is given for each type of tooth

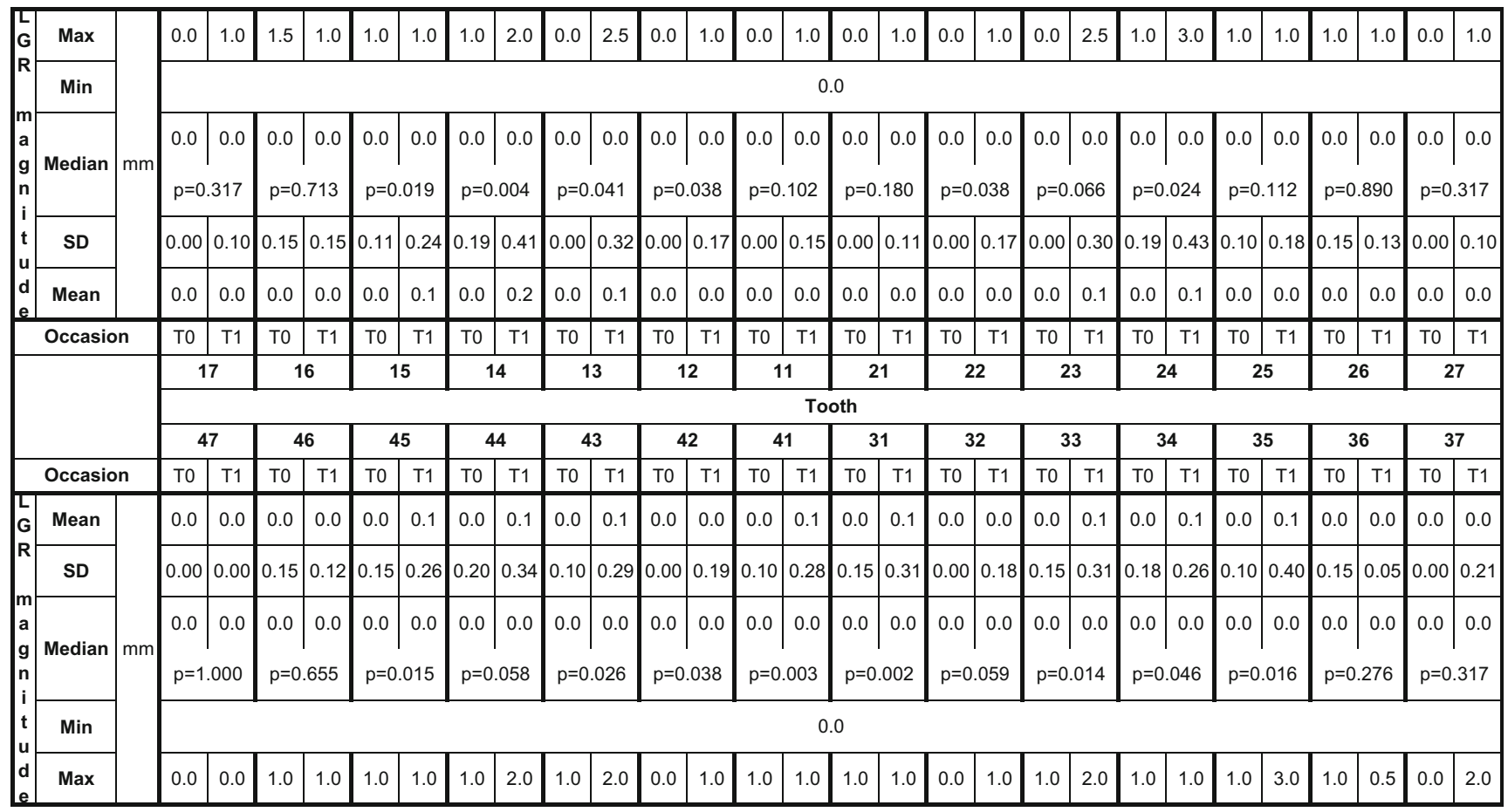

right second premolars as well as the lower central incisors with a prevalence of $12.1-20.2 \%$; however, only $1.0-2.0 \%$ of the premolars and none of the incisors exhibited LGR $\geq$ $2.0 \mathrm{~mm}$ (Fig. 2a, b; Table 1).

\section{Incidence of LGR (T0 and T1: $n=94)$}

From pre-Tx to post-retention (T0-T1), and thus over a total observation period of approximately 4.5 years, an overall mean LGR incidence for magnitude $\geq 0.5 \mathrm{~mm}$ of $5.3 \%$ was determined (Table 1). The respective incidence value for LGR $\geq 2.0 \mathrm{~mm}$ was $0.4 \%$.

The highest LGR incidence values for magnitude $\geq 0.5 \mathrm{~mm}$ were seen for the upper right premolars and the lower central incisors: 9.9-14.9\% (Fig. 1; Table 1). Comparing the pre-Tx (T0) and post-retention (T1) data, the prevalence changes were significant $(p \leq 0.05)$ for 10 of the 28 different teeth (Table 1) and the magnitude changes in 14 of the 28 different teeth (Table 2). The respective post-retention median/mean magnitude was $0.00 / 0.06 \mathrm{~mm}$ (Table 2).

\section{Discussion}

The present study is the first to assess the prevalence, incidence and magnitude of LGR in all teeth 17-47 during class II:2 Herbst-MBA Tx and retention.

\section{Subjects}

Study casts of all class II: 2 patients who underwent HerbstMBA Tx at one single study centre during a period of 27 years were investigated. The study design was retrospective; so, it was not possible to control all variables that might have influenced LGR development as a multifactorial occurrence. For example, the amount of mandibular advancement, periodontal morphology/susceptibility to LGR and patient compliance could not be analysed. Still, the sample was homogenous in terms of the underlying malocclusion class II: 2 and the general Tx approach being non-extraction. The fact that Tx had been performed by different practitioners using two different types of straight-wire MBAs - which might have affected torque-should not interfere with the objective to evaluate the effect of Herbst-MBA Tx on the prevalence, incidence and magnitude of LGR. Due to severe gingival swelling/ hyperplasia being often present upon debonding, the study casts from that occasion were not used and the measurements were confined to the post-retention study casts. In any case, the inclusion of patients was performed irrespective of Tx outcome.

\section{Method}

The distance between the cemento-enamel junction and the deepest point of the gingival margin/recession was determined 


\section{a}

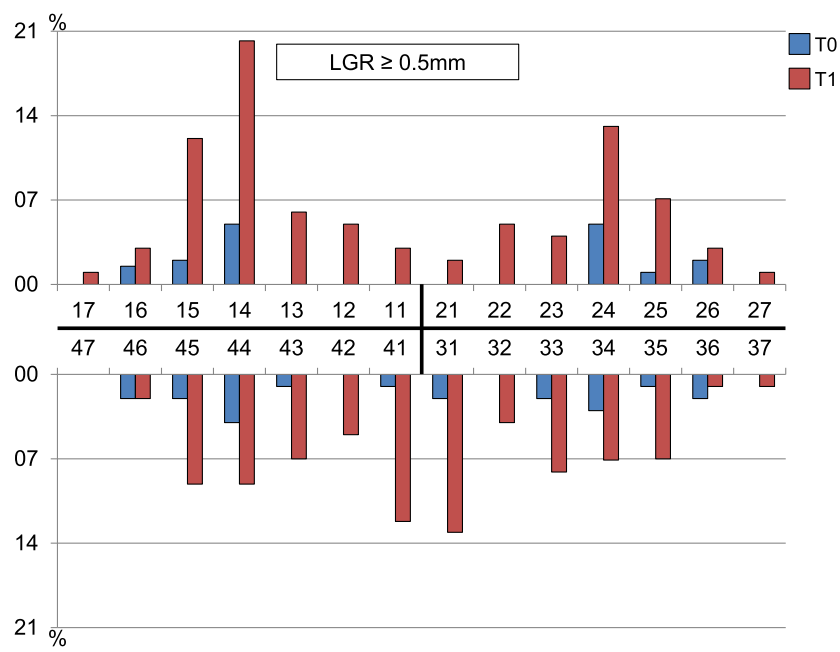

b

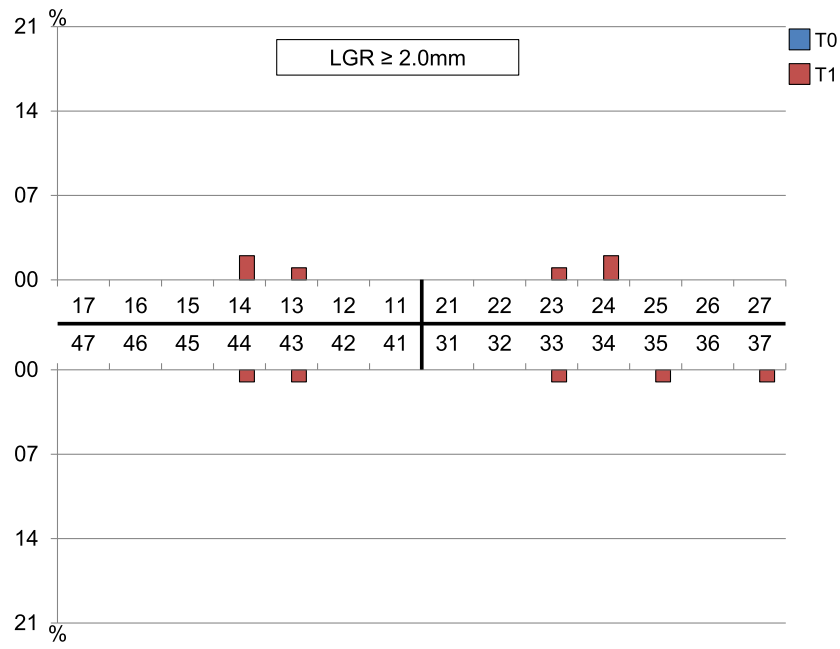

Fig. 2 Prevalence (\%) of labial gingival recession for the teeth $17-47$ before Tx (T0) and after Herbst-MBA Tx and a retention period of $\geq$ 24 months (T1) for LGR with a magnitude $\geq 0.5 \mathrm{~mm}(\mathbf{a}) / 2.0 \mathrm{~mm}$ (b) in 94 individuals

on all fully erupted teeth. All these linear measurements were performed by one single investigator with high consistency (Kendall's Tau $=0.84$ ), the method error of $0.07 \pm 0.08$ was rather low. Therefore, the data can be regarded objective.

Measurements of gingival recessions performed on study casts were determined to show a high correlation with those from clinical assessment [22]. Nevertheless, gingival swelling and artefacts occurring during study cast preparation might affect the accuracy of the measurements. On the other hand, an intraobserver reliability of 0.80 to 1.00 and an interobserver agreement of $0.67-1.00$ were determined in a similar investigation where pre- and post-Tx study casts were evaluated, proving good reliability [23].

\section{Results-prevalence}

The data on LGR prevalence in adolescents available in the literature are limited. The pre-Tx overall LGR prevalence of $1.4 \%$ determined from 2601 teeth is in concordance with the pre-Tx prevalence of $1.7 \%$ described after assessing study casts of 302 similarly aged orthodontic - mainly class IIpatients [23]. A value of $1.1 \%$ was determined in a class II:1 sample with a total of 12,573 teeth before Herbst-MBA Tx [18]. All these values are lower than the prevalence of 5.6\% determined from 100 non-orthodontic 12-year old Finns after a clinical examination [24]. The reason for this difference is unknown, but both the different assessment methods and the analysed populations' variation might be contributing factors.

After approximately 4.5 years of Tx plus retention at age 20.2 \pm 5.6 years, an overall prevalence value of $6.7 \%$ was found for LGR with a magnitude $\geq 0.5 \mathrm{~mm}$ in the present sample with 2601 teeth. In the literature, a rate of $20.2 \%$ was described for a sample of 302 similarly aged orthodontic (mainly class II) patients after a similar observation period [23]. For class II:1 Herbst-MBA Tx, the respective value was $5.3 \%$ after 5 years of Tx and retention [18]. Overall, LGR prevalence values in the literature range between 1.6 and $13.8 \%$ for mainly untreated samples of similar age (Table 3) [7, 24-29].

The finding of particularly high LGR prevalence values of $12.2-13.1 \%$ for the lower central incisors is at least partially in accordance with the literature when looking at data of orthodontically treated class II:1 samples (Herbst-MBA Tx 1217\%, mean age 19 years [18]; only Herbst Tx 15-22\%, mean age 14 years [15]). Specific reports for other appliances respectively other Tx protocols do not exist. Other-according to the references - mainly untreated samples of similar age (mean 18-29 years) exhibit values between 2 and 9\% [7, 27, 29]. Distinctly higher values of up to $33 \%$ were determined in a Brazilian urban population aged 14 to 29 years without information given on the history of orthodontic Tx [26]. Thus, the values determined for the lower incisors in the present sample after Herbst-MBA Tx are not distinctly higher than those for treated and untreated samples in the literature. It can therefore be assumed that Herbst-MBA Tx is not a risk factor for the development of LGR in class II:2 malocclusions.

The upper first premolars exhibited notably high LGR prevalence values of $13.1-20.2 \%$ as well. While these values are slightly higher than most available data in the literature for upper first premolars in orthodontically treated and untreated subjects of similar age ranging between 6.5 and $15.0 \%$ [7, 23, 27], a much higher prevalence value of $32.6 \%$ obtained from a sample of dental students has also been published [29]. For class II: 1 patients with the identical Tx approach, the respective prevalence values of $8.0-8.5 \%$ were much lower [18]. Therefore, the cause for this high LGR prevalence in class II:2 seems not to lie in the Herbst-MBA Tx protocol but in the morphologic difference between class II:1 and class II:2 
Table 3 Labial gingival recession prevalence data available in the literature for adolescents/young adults. The reference number, sample characteristics, and prevalence values (\%) of comparable samples (age) are given

\begin{tabular}{|c|c|c|c|c|c|c|}
\hline \multirow[t]{2}{*}{ Reference } & \multicolumn{4}{|l|}{ Sample } & \multicolumn{2}{|c|}{ LGR prevalence } \\
\hline & Origin & Orthodontic Tx & $n$ & Mean age (years) & Type of teeth & $\%$ \\
\hline \multirow[t]{3}{*}{7} & \multirow[t]{3}{*}{ Israel } & \multirow[t]{3}{*}{$27.4 \%$ treated } & \multirow[t]{3}{*}{303} & \multirow[t]{3}{*}{$18-22$} & $17-47$ & 1.6 \\
\hline & & & & & 31,41 & $\approx 4.5-6.8$ \\
\hline & & & & & 14,24 & $\approx 10.2-13.5$ \\
\hline \multirow[t]{2}{*}{15} & \multirow[t]{2}{*}{ Sweden } & Untreated & \multirow[t]{2}{*}{98} & 13 & 31,41 & $12.2-18.4 \%$ \\
\hline & & $100.0 \%$ treated & & 14 & 31,41 & $\approx 15.3-22.4 \%$ \\
\hline \multirow[t]{6}{*}{18} & \multirow[t]{6}{*}{ Germany } & \multirow[t]{3}{*}{ Untreated } & \multirow[t]{3}{*}{460} & \multirow[t]{3}{*}{14} & $17-47$ & $1.1 \%$ \\
\hline & & & & & 31,41 & $\approx 5.0$ \\
\hline & & & & & 14,24 & $\approx 2.0$ \\
\hline & & \multirow[t]{3}{*}{$100.0 \%$ treated } & \multirow[t]{3}{*}{187} & \multirow[t]{3}{*}{19} & $17-47$ & 5.3 \\
\hline & & & & & 31,41 & $\approx 15.0-16.0$ \\
\hline & & & & & 14,24 & $\approx 8.0-8.5$ \\
\hline \multirow[t]{6}{*}{23} & \multirow[t]{6}{*}{ Netherlands } & \multirow[t]{3}{*}{ Untreated } & \multirow[t]{3}{*}{302} & \multirow[t]{3}{*}{14} & $17-47$ & 1.7 \\
\hline & & & & & 31,41 & $\approx 0.0-0.2$ \\
\hline & & & & & 14,24 & $\approx 0.0-0.2$ \\
\hline & & \multirow[t]{3}{*}{$100.0 \%$ treated } & \multirow[t]{3}{*}{302} & \multirow[t]{3}{*}{19} & $17-47$ & 20.2 \\
\hline & & & & & 31,41 & $\approx 3.5-4.2$ \\
\hline & & & & & 14,24 & $\approx 6.5$ \\
\hline \multirow[t]{2}{*}{24} & \multirow[t]{2}{*}{ Finland } & \multirow[t]{2}{*}{ No information } & 100 & 12 & $17-47$ & 5.6 \\
\hline & & & 100 & 17 & $17-47$ & 13.8 \\
\hline 25 & Norway & No information & n.a. & $20-21$ & $17-47$ & 5.8 \\
\hline & Sri Lanka & No information & n.a. & $18-19$ & $17-47$ & 1.6 \\
\hline 26 & Brazil & No information & 263 & $14-19$ & $17-47$ & 2.9 \\
\hline 27 & Sweden & No information & n.a. & $18-29$ & $17-47$ & 7.0 \\
\hline & & & & & 31,41 & $\approx 3.0$ \\
\hline & & & & & 14,24 & $\approx 10.0-15.0$ \\
\hline 28 & USA & No information & 77 & $16-25$ & $17-47$ & 9.5 \\
\hline 29 & France & No information & 100 & $19-26$ & $17-27$ & 11.7 \\
\hline & & & & & 31,41 & 9.0 \\
\hline & & & & & 14,24 & $28.1-32.6$ \\
\hline
\end{tabular}

malocclusions. Class II:2 malocclusions typically feature a large maxillary apical base especially in the transverse dimension and relative to the lower jaw [30, 31]. In addition, class II:2 malocclusions often present small teeth in comparison to the well-developed jaw [32]. As a consequence, establishing a normal transverse upper to lower occlusal relationship and closing all spaces in the upper arch results in slightly palatally inclined premolars and molars, which in turn predisposes them to the development of LGR.

\section{Results-incidence}

Regarding the incidence of LGR with a magnitude $\geq 0.5 \mathrm{~mm}$, an overall rate of $5.3 \%$ was found for the total observation period of approximately 4.5 years. Previous data in the literature report LGR incidence rates of $3-10 \%[15,18,33]$ for orthodontically treated and 8\% [24] for orthodontically untreated samples.

Looking specifically at the lower central incisors, an overall incidence of $4.0-11.1 \%$ for LGR with a magnitude $\geq$ $0.5 \mathrm{~mm}$ was determined. This rate corresponds to data in the literature: $3.0 \%$ during class II:1 Herbst Tx [15], 10.4-11.4\% during class II: 1 Herbst-MBA Tx [18], and 7.0-10.0\% during class I/II non-extraction Tx in adults [33].

Even if some articles in the literature conclude that orthodontic tooth movement might increase the risk for LGR development [6, 7, 34-36], the data of the current study and their comparison with the literature show that Herbst-MBA Tx cannot generally be considered a clinically relevant risk factor for LGR development. Lesions beyond average might obviously emerge in single patients, but this is probably true for any kind of orthodontic 
Tx, especially as LGR are induced by more than a single factor $[25,37-40]$.

\section{Results-magnitude}

Post-retention, the mean LGR magnitude of the present sample was $0.06 \pm 0.25 \mathrm{~mm}$ and therefore similar as in other orthodontic patients $(0.1 \pm 0.1 \mathrm{~mm}, n=222,2.7$ years post-Tx at age $14-19$ years [18]; $0.1 \pm 0.3 \mathrm{~mm}, n=64,4.6$ years post-Tx at age 18-26 years [34]) and even smaller than in untreated populations $(1.2 / 2.0 \mathrm{~mm}$, untreated $20-21$ years old Norwegians/18-19 years old Sri Lankans [25]).

Looking specifically at lower incisors, very little has been published so far. Nevertheless, the present magnitude (mean $0.0-0.1 \mathrm{~mm}$, maximum $1.0 \mathrm{~mm}$ ) is similar or lower than in class II: 1 patients after Herbst-MBA Tx (mean 0.1-0.2 mm, maximum $4.0 \mathrm{~mm}$ [18]) respectively in other samples of orthodontically treated patients observed for $4-9$ years where the values in the literature range between $\approx 0.6 \mathrm{~mm}[41]$, $0.6-1.1 \mathrm{~mm}$ [12] and $0.9-1.0 \mathrm{~mm}$ [42]. This is also true for the corresponding values determined from an orthodontically untreated sample (mean 1.0-1.2 mm, maximum $3.0 \mathrm{~mm}$ [29]).

\section{Limitations}

The reduced number of complete sets of study casts when compared to the pre-Tx patient sample is certainly a limitation. In addition, the retrospective study design, which includes the fact that only study casts and no data on oral hygiene during Tx were assessed, limits the reliability of the data. And finally, the study design also comes with a high risk of reporting and performance bias, which should not be neglected even if the overall LGR incidence and magnitude values are low.

\section{Conclusion}

During class II: 2 correction, the mean prevalence of teeth with LGR $\geq 0.5 \mathrm{~mm}$ increased from $1.4 \%$ before Tx to $6.7 \%$ after 24 months of Herbst-MBA Tx plus 29 months of retention $(\approx 4.5$ years). The highest incidence was seen for lower central incisors and upper right premolars $(11.1 / 14.9 \%)$. However, as the overall mean magnitude after HerbstMBA Tx plus retention was $0.06 \mathrm{~mm}$, the clinical relevance can be considered as low to insignificant.

Funding Information Open Access funding provided by Projekt DEAL.

\section{Compliance with ethical standards}

Conflict of interest The authors declare that they have no conflict of interest.
Ethical approval Ethical approval 80/14) was obtained from the institution and all procedures performed were in accordance with the ethical standards of the institutional and/or national research committee and with the 1964 Helsinki declaration and its later amendments or comparable ethical standards.

Informed consent For this type of study, formal consent is not required.

Open Access This article is licensed under a Creative Commons Attribution 4.0 International License, which permits use, sharing, adaptation, distribution and reproduction in any medium or format, as long as you give appropriate credit to the original author(s) and the source, provide a link to the Creative Commons licence, and indicate if changes were made. The images or other third party material in this article are included in the article's Creative Commons licence, unless indicated otherwise in a credit line to the material. If material is not included in the article's Creative Commons licence and your intended use is not permitted by statutory regulation or exceeds the permitted use, you will need to obtain permission directly from the copyright holder. To view a copy of this licence, visit http://creativecommons.org/licenses/by/4.0/.

\section{References}

1. Batenhorst KF, Bowers GM, Williams JE Jr (1974) Tissue changes resulting from facial tipping and extrusion of incisors in monkeys. $\mathrm{J}$ Periodontol 45:660-668

2. Steiner GG, Pearson JK, Ainamo J (1981) Changes of the marginal periodontium as a result of labial tooth movement in monkeys. $\mathrm{J}$ Periodontol 52:314-320

3. Papageorgiou SN, Papadelli AA, Eliades T (2018) Effect of orthodontic treatment on periodontal clinical attachment: a systematic review and meta-analysis. Eur J Orthod 40:176-184

4. Tepedino M, Franchi L, Fabbro O, Chimenti C (2018) Postorthodontic lower incisor inclination and gingival recession-a systematic review. Prog Orthod 19:17

5. Bollen AM (2008) Effects of malocclusions and orthodontics on periodontal health: evidence from a systematic review. J Am Dent Assoc 72:912-918

6. Renkema AM, Fudalej PS, Renkema AA, Abbas F, Bronkhorst E, Katsaros C (2013) Gingival labial recessions in orthodontically treated and untreated individuals: a case-control study. J Clin Periodontol 40:631-637

7. Slutzkey S, Levin L (2008) Gingival recession in young adults: occurrence, severity, and relationship to past orthodontic treatment and oral piercing. Am J Orthod Dentofac Orthop 134:652-656

8. Årtun J, Krogstad O (1987) Periodontal status of mandibular incisors following excessive proclination. A study in adults with surgically treated mandibular prognathism. Am J Orthod Dentofac Orthop 91:225-232

9. Ciavarella D, Tepedino M, Gallo C, Montaruli G, Zhurakivska K, Coppola L, Troiano G, Chimenti C, Laurenziello M, Lo Russo L (2017) Post-orthodontic position of lower incisors and gingival recession: a retrospective study. J Clin Exp Dent 9:e1425-e1430

10. Pernet F, Vento C, Pandis N, Kiliaridis S (2019) Long-term evaluation of lower incisors gingival recessions after orthodontic treatment. Eur J Orthod 41:559-564

11. Morris JW, Campbell PM, Tadlock LP, Boley J, Buschang PH (2017) Prevalence of gingival recession after orthodontic tooth movements. Am J Orthod Dentofac Orthop 151:851-859

12. Renkema AM, Navratilova Z, Mazurova K, Katsaros C, Fudalej PS (2015) Gingival labial recessions and the post-treatment proclination of mandibular incisors. Eur J Orthod 37:508-513 
13. Bock NC, Ruf S, Wiechmann D, Jilek T (2014) Herbst plus lingual versus Herbst plus labial: a comparison of occlusal outcome and gingival health. Eur J Orthod 38:478-484

14. Pancherz H (1982) The mechanism of class II correction in Herbst appliance treatment. A cephalometric investigation. Am J Orthod 82:104-113

15. Ruf S, Hansen K, Pancherz H (1998) Does orthodontic proclination of lower incisors in children and adolescents cause gingival recession? Am J Orthod Dentofac Orthop 114:100-106

16. Schwartz JP, Raveli TB, Schwartz-Filho HO, Raveli DB (2016) Changes in alveolar bone support induced by the Herbst appliance: a tomographic evaluation. Dental Press J Orthod 21:95-101

17. von Bremen J, Ludwig B, Ruf S (2015) Anchorage loss due to Herbst mechanics-preventable through miniscrews? Eur J Orthod 37:462-466

18. Bock NC, Ruehl J, Ruf S (2019) Prevalence, magnitude, and incidence of labial gingival recession with Herbst-Multibracket appliance treatment: (a retrospective cohort study). Angle Orthod 89: 535-543

19. Bock NC, Saffar M, Hudel H, Evälahti M, Heikinheimo K, Rice DPC, Ruf S (2018) Long-term effects of class II orthodontic treatment on oral health. J Orofac Orthop 79:96-108

20. Pancherz H, Bjerklin K (2014) Mandibular incisor inclination, tooth irregularity, and gingival recessions after Herbst therapy: a 32-year follow-up study. Am J Orthod Dentofac Orthop 146:310-318

21. Kuckartz U, Rädiker S, Ebert T, Schiehl J (2010) Statistik. Eine verständliche Einführung, 1 st edn. VS Verlag für Sozialwissenschaften, Springer Fachmedien, Wiesbaden

22. Renkema AM, Fudalej PS, Renkema A, Bronkhorst E, Katsaros C (2012) Gingival recessions and the change of inclination of mandibular incisors during orthodontic treatment. Eur J Orthod 35:249255

23. Renkema AM, Fudalej PS, Renkema A, Kiekens R, Katsaros C (2013) Development of labial gingival recessions in orthodontically treated patients. Am J Orthod Dentofac Orthop 143:206-212

24. Ainamo J, Paloheimo L, Nordblad A, Murtomaa H (1986) Gingival recession in schoolchildren at 7,12 and 17 years of age in Espoo, Finland. Comm Dent Oral Epidemiol 14:283-286

25. Löe H, Ånerud Å, Boysen H (1992) The natural history of periodontal disease in man: prevalence, severity, and extent of gingival recession. J Periodontol 63:489-495

26. Susin C, Haas AN, Oppermann RV, Haugejorden O, Albandar JM (2004) Gingival recession: epidemiology and risk indicators in a representative urban Brazilian population. J Periodontol 75:13771386

27. Serino G, Wennström JL, Lindhe J, Eneroth L (1994) The prevalence and distribution of gingival recession in subjects with a high standard of oral hygiene. J Clin Periodontol 21:57-63

28. Gorman WJ (1967) Prevalence and etiology of gingival recession. J Clin Periodontol 38:316-322
29. Tenenbaum H (1982) A clinical study comparing the width of attached gingiva and the prevalence of gingival recessions. J Periodontol 9:86-92

30. Hausser E (1953) Zur Ätiologie und Genese des Deckbisses. Fortschr Kieferorthop 14:154-161

31. Walkow TM, Peck S (2002) Dental arch width in class II division 2 deep-bite malocclusion. Am J Orthod Dentofac Orthop 122:608 613

32. Peck S, Peck L, Kataja M (1998) Class II division 2 malocclusion: a heritable pattern of small teeth in well-developed jaws. Angle Orthod 68:9-20

33. Melsen B, Allais D (2005) Factors of importance for the development of dehiscences during labial movement of mandibular incisors: a retrospective study of adult orthodontic patients. Am J Orthod Dentofac Orthop 127:552-561

34. Levin L, Samorodnitzky-Naveh GR, Machtei EE (2008) The association of orthodontic treatment and fixed retainers with gingival health. J Periodontol 79:2087-2092

35. Djeu G, Hayes C, Zawaideh S (2002) Correlation between mandibular central incisor Proclination and gingival recession during fixed appliance therapy. Angle Orthod 72:238-245

36. Joss-Vassalli I, Grebenstein C, Topouzelis N, Sculean A, Katsaros C (2010) Orthodontic therapy and gingival recession: a systematic review. Orthod Craniofacial Res 13:127-141

37. Allais D, Melsen B (2003) Does labial movement of lower incisors influence the level of the gingival margin? A case-control study of adult orthodontic patients. Eur J Orthod 25:343-352

38. Litsas GM, Acar A, Erverdi N, Athanasiou A (2005) Mucogingival considerations and labial movement of lower incisors in orthodontic patients. Hell Orthod Rev 8:31-40

39. Seong J, Bartlett D, Newcombe RG, Claydon NCA, Hellin N, West NX (2018) Prevalence of gingival recession and study of associated related factors in young UK adults. J Dent 76:58-67

40. Smith RG (1997) Gingival recession. Reappraisal of an enigmatic condition and a new index for monitoring. J Clin Periodontol 24: 201-205

41. Årtun J, Grobéty D (2001) Periodontal status of mandibular incisors after pronounced orthodontic advancement during adolescence: a follow-up evaluation. Am J Orthod Dentofac Orthop 119:2-10

42. Antonarakis GS, Joss CU, Triaca A, Kuijpers-Jagtman AM, Kiliaridis S (2017) Gingival recessions of lower incisors after proclination by orthodontics alone or in combination with anterior mandibular alveolar process distraction osteogenesis. Clin Oral Investig 21:2569-2579

Publisher's note Springer Nature remains neutral with regard to jurisdictional claims in published maps and institutional affiliations. 